\title{
FORMATIVE ELECTRONIC ASSESSMENTS DURING COVID-19 LOCKDOWN IN SECOND PHASE MEDICAL UNDERGRADUATES
}

\author{
DHANYA SASIDHARAN PALAPPALLIL ${ }^{1 *}$, DEEPA SUJATHA ${ }^{2}$ \\ ${ }^{1}$ Department of Pharmacology, Government Medical College, Kottayam, Kerala, India. ${ }^{2}$ Department of Pathology, Government Medical \\ College, Kottayam, Kerala, India. Email: drspdhanya@gmail.com
}

Received: 10 March 2021, Revised and Accepted: 20 April 2021

\section{ABSTRACT}

Objective: Electronic learning and assessment was embraced in medical education worldwide following the COVID-19 pandemic. This study was done to determine the perceptions of medical undergraduates on formative electronic assessments conducted during COVID-19 lockdown and to estimate the mean marks scored in these assessments.

Methods: This was a descriptive study done for a period of 3 months on online platform. Six online formative assessments were conducted on Google Forms or Kahoot. A questionnaire was administered as Google Form to collect the perceptions of the participants on perceived ease of use of platform, attitude, and practice adopted in online assessments. Data were analyzed using SPSS 16.

Results: The response rate was $97.7 \%$. Kahoot was perceived to be easier with lesser technical glitches and privacy concerns as compared to Google, while it was equivocal in terms of access assessment links, output storage, display clarity, overall user interface, network issues, need for computer literacy, and eyestrain caused. The participants had a positive attitude regarding the usefulness of online assessments however majority liked the traditional assessments more than the online assessments. While less than one-third (22\%) had copy pasted some answers, more than half (54.4\%) had referred to internet and more than three quarter (79.6\%) had referred to textbooks/power points/notes while attending online assessments.

Conclusion: The participants felt that Google Forms and Kahoot were comparable online assessment tools except for difficulty in filling, privacy concerns, and technical issues on Google Forms. The usefulness of online assessments was embraced by the participants but they felt that the traditional assessments were to be continued, while attending online assessments some students had referred to the internet or study materials.

Keywords: Formative, Electronic, Assessment, Google form, Kahoot, Feedback, COVID-19.

(C) 2021 The Authors. Published by Innovare Academic Sciences Pvt Ltd. This is an open access article under the CC BY license (http://creativecommons.org/ licenses/by/4.0/) DOI: http://dx.doi.org/10.22159/ajpcr.2021v14i7.41430. Journal homepage: https://innovareacademics.in/journals/index.php/ajpcr

\section{INTRODUCTION}

Electronic assessment (e-assessment) is defined as the use of end-toend electronic methods for the whole assessment processes from the presentation of questions to the saving of the learner's responses [1]. This means that the design, test implementation, recording the response, and providing the feedback are all completed using electronic devices [2]. Computer-based assessment (CBA) has emerged in recent years as a viable alternative to traditional assessment techniques. It has also infiltrated and influenced the medical curriculum where it has been employed for assessment tasks [3]. Two hundred and eighty Medical Students of Imperial College of London had undergone unsupervised online summative exams in March 2020 with the implementation of COVID-19 lockdown, a worldwide first [4]. With the implementation of series of staged lockdown, the Kerala University of Health Sciences initiated online learning in April 2020. Under these circumstances change of learning from the traditional learning to online synchronous and asynchronous platforms have enabled the medical students to be in touch with the content of the curriculum as well as with teachers. However, the apprehensions regarding the connectivity and content delivery to the students need to be addressed by formative assessments which also can be done only through the online platform in the current stage. The objective of this study was to determine the perceived ease of use of online platform, attitude, and practice about online assessments on Google Fill Out Forms and Kahoot platform among $2^{\text {nd }}$ year medical undergraduates using a structured questionnaire. We have also tried to estimate the mean marks scored by $2^{\text {nd }}$ year medical undergraduates in various e-assessments done during COVID-19 lockdown period.

\section{METHODS}

This was a descriptive study done for a period of 3 months from August to October 2020 on online platform conducted by the Departments of Pharmacology and Pathology, Government Medical College, Kottayam. The second phase medical undergraduates $(n=130)$ formed the sample population. All the students in sample population willing to participate in online assessment were included in the study after IRB clearance (IRB No: 37/2020 dated 20/08/2020) and they underwent six formative online assessments.

Online assessment in this study was defined as an assessment of 3045 min duration using Multiple Choice Question (MCQ), Match the Following, True/False, Short Answer Questions (SAQ), or One word answers in the subject of Pharmacology or Pathology.

Online assessments were conducted using Google fillout forms and Kahoot online quiz [5,6]. Questionnaire was prepared based on previous studies $[7,8]$. The construct validity was done by formal opinion on each item. The questionnaire was piloted among additional batch students $(\mathrm{n}=12)$ from same setting. The level of perception of individual respondents was assessed using the cumulative score of a five point Likert scale, with an increasing order of agreement. The response to each question was presumed to be the score of that question. Reliability analysis showed a Cronbach's coefficient alpha of 0.79 for ease of use of online platform, 0.77 for attitude and 0.6 for practice.

Online informed consent was obtained from the participants willing to be enrolled in the study. The investigators administered six online 
assessments to the participants on Google Fillout Form and Kahoot platform. The questions were shuffled and the options in the MCQs were also shuffled and each assessment lasted for 30-45 min. The tests were announced at least 5 days before the date of exam. The formative feedback on the performance and scores were mailed to the participants within 2 days of submission of their responses for assessments in Google Fillout form whereas the scores were released immediately for assessments on Kahoot platform. The questionnaire for collecting the perceptions and practices on formative online assessments was administered as Google fill out form after the completion of six online assessments. The questionnaires which were partially filled were excluded from the study. The data were entered into Excel sheet and analyzed using SPSS 16 for windows (SPSS Inc., Chicago, USA). Perceived ease of use of online platform, attitude and practice regarding online assessments are expressed as proportion and median scores. Mann-Whitney U-test was used to compare the perceptions about Google Fill Out Forms and Kahoot platform. The marks are expressed as mean \pm standard deviation.

\section{RESULTS}

Three out of the 130 participants who denied consent and submitted unfilled forms were excluded from the study; hence, the response rate was 127/130 (97.7\%). There were 78 (61.4\%) female and 49 (38.6\%) male participants. The mean age was $21.1 \pm 1.2$ years.

The domain perceived ease of the use of platform was divided into two parts Convenience to Use the Platform and Issues and Challenges Faced during the online assessment in that platform. As shown in Table 1, the access to the links of assessment, storage of output, clarity in display, overall user interface had comparable median scores however Kahoot had a statistically significant ease of entering answers in assessment as compared to Google Fill Out Form $(\mathrm{p}<0.001)$. As shown in Table 2, while using Google Fill Out Forms the participants felt that their privacy was compromised and also encountered serious technical glitches $(\mathrm{p}=0.05)$ compared to Kahoot. There was no difference in the challenges faced because of network issues, computer literacy or eyestrain between Google Fill Out Form and Kahoot.

54 (42.5\%) preferred Google Fill Out Form, 66 (52\%) preferred Kahoot, and 7 (5.5\%) did not give any preference. Only 7 (5.5\%) thought that online assessments are right choice in future medical education assessments, $78(61.4 \%)$ thought it was not a right choice and $42(33.1 \%)$ it may be used.

As shown in Table 3, 59 (46.5\%) agreed that online assessments helped them in preparing the topic during COVID-19 lockdown, 69 (54.3\%) agreed it was good for self-directed learning, $65(51.2 \%)$ agreed that feedback received during the online formative assessments made them work better for the next time, $62(48.8 \%)$ agreed that the online assessments motivated them to learn during lockdown, 59 (46.5\%) agreed that the online assessments helped them to learn independently,
$49(38.6 \%)$ agreed that they attended the assessments sincerely, and $46(36.2 \%)$ agreed that time allotted for assessment was sufficient. However, 63 (49.6\%) were neutral when asked about apprehension about online assessment, 50 (39.4\%) disagreed to the statement that they were better than traditional assessment, 49 (38.6\%) were neutral on the feedback received by the faculty, $48(37.8 \%)$ agreed that they helped in receiving feedback from faculty, $56(44.1 \%)$ were neutral on the statement that feedback made them anxious, 45 (35.4\%) agreed that there was no enough time to prepare for assessments, and 38 (29.9\%) were neutral about liking online assessments and 33 disagreed and 31 agreed to the statement "I don't like online assessments."

As shown in Fig. 1, only 61 (48\%) had revised the topics before online assessment. Even though majority $89(70.1 \%)$ denied copy pasting and $10(7.9 \%)$ gave a neutral answer $28(22 \%)$ had copy pasted some answers. Similarly, $69(54.4 \%)$ had referred to internet and $101(79.6 \%)$ had referred to textbooks/PowerPoints/notes while attending online assessments. Timely submission of assessments was done by 62 (48.8\%), $88(69.3 \%)$ had gone through the feedback of the assessments and 59 (46.4\%) had saved the assessment feedbacks for future use.

In an open ended question which sought the reason for copying in those who stated that they had copied, reasons quoted were inadequacy of time, confusion in the answer, lack of confidence in attending test, inability to skip unknown questions (all questions were compulsory), inadequate preparation, and for scoring better in the fear that the marks of test will be used for internal assessment and difficulty in typing whole answer for short notes on mobile devices.

Table 4 summarizes the online assessments done during the study period. On Kahoot platform Test 1-Autonomic Nervous System (Pharmacology), Test 2-General Pharmacology (Pharmacology), Test 3-GIT (Pathology) was conducted and on Google Fillout Form Test 1-Central Nervous System (Pharmacology), Test 2-Anticoagulants (Pharmacology), and Test 3-Male and Female Genital System (Pathology) were conducted. The mean marks were not compared because the topics were different. However, as depicted in Fig. 2, the participants scored higher mean marks in Google Fill Out Form when compared to Kahoot.

The open question on suggestions to improve the online assessment was responded by 94 participants. Eighteen $(14.2 \%)$ requested for smaller topics for assessment, 16 (12.6\%) requested more time for attempting the online assessments and 10 (7.9\%) demanded more preparation time. Other suggestions given were the need for online discussions and immediate release of answers after assessments, incorporation of simpler MCQs rather than tough questions, incorporation of SAQ not to use these assessment for internal marks and use it only for self-assessment, the need of faculty supervision to prevent copying, restricting Kahoot responses to one per person as

Table 1: Convenience to use Google Fill Out Form versus Kahoot

\begin{tabular}{|c|c|c|c|c|c|c|}
\hline \multicolumn{2}{|c|}{ Statement and online assessment platforms } & \multirow{2}{*}{$\begin{array}{l}\text { Median } \\
\left(1^{\text {st }} \mathbf{I Q}\right. \\
\left.\mathbf{3}^{\text {rd }} \mathbf{I Q}\right) \\
4(4.5)\end{array}$} & \multirow{2}{*}{$\begin{array}{l}\text { Mean rank } \\
132.37\end{array}$} & \multirow{2}{*}{$\begin{array}{l}\text { Mean sum of ranks } \\
16811.50\end{array}$} & \multirow{2}{*}{$\begin{array}{l}\text { U statistic } \\
7445.50\end{array}$} & \multirow{2}{*}{$\begin{array}{l}\text { p value } \\
0.24\end{array}$} \\
\hline Access to link of assessment & Google Fill Out & & & & & \\
\hline \multirow{3}{*}{ Entering answers in the assessments } & Kahoot & $4(4.5)$ & 122.63 & 15573.50 & & \\
\hline & Google Fill Out & $4(2.4)$ & 111.51 & 14161.50 & 6033.500 & $<0.001$ \\
\hline & Kahoot & $4(2.5)$ & 143.49 & 18223.50 & & \\
\hline \multirow[t]{2}{*}{ Storage of output (valued answer sheet) } & Google Fill Out & $4(2.4)$ & 132.02 & 16766.50 & 7490.500 & 0.31 \\
\hline & Kahoot & $3(2.4)$ & 122.98 & 15618.50 & & \\
\hline \multirow{2}{*}{ Clarity in display of menu option } & Google Fill Out & $4(3.5)$ & 128.15 & 16275.50 & 7981.500 & 0.88 \\
\hline & Kahoot & $4(3.5)$ & 126.85 & 16109.50 & & \\
\hline \multirow{2}{*}{ Overall user interface } & Google Fill Out & $4(2.4)$ & 129.12 & 16398.00 & 7859.000 & 0.71 \\
\hline & Kahoot & $4(2.4)$ & 125.88 & 15987.00 & & \\
\hline
\end{tabular}

1-very inconvenient and difficult, 2-somewhat inconvenient and difficult, 3-don't know, 4-somewhat convenient, and easy, 5-very convenient and easy. 
Table 2: Issues and challenges faced during the online assessment with Google Fill Out Form versus Kahoot

\begin{tabular}{|c|c|c|c|c|c|c|}
\hline Statement and online assessment platforms & & $\begin{array}{l}\text { Median } \\
\left(1^{\text {st }} I Q\right. \\
\left.3^{\text {rd }} I Q\right)\end{array}$ & Mean rank & Mean sum of ranks & U statistic & p value \\
\hline \multirow[t]{2}{*}{ Privacy of the user is compromised } & Google Fill Out & $3(2.4)$ & 135.71 & 17235.50 & \multirow[t]{2}{*}{7021.500} & \multirow[t]{2}{*}{0.05} \\
\hline & Kahoot & $3(2.3)$ & 119.29 & 15149.50 & & \\
\hline \multirow[t]{2}{*}{ Encountered technical glitches and had to redo } & Google Fill Out & $4(3.5)$ & 136.09 & 17283 & \multirow[t]{2}{*}{6974.000} & \multirow[t]{2}{*}{0.05} \\
\hline & Kahoot & $3(2.4)$ & 118.91 & 15102 & & \\
\hline \multirow[t]{2}{*}{ Network issues affected my online submissions } & Google Fill Out & $2(2.3)$ & 131.37 & 16683.50 & \multirow[t]{2}{*}{7573.500} & \multirow[t]{2}{*}{0.38} \\
\hline & Kahoot & $4(2.4)$ & 123.63 & 15701.50 & & \\
\hline \multirow[t]{2}{*}{ Caused eye strain while attempting the assessment } & Google Fill Out & $3(2.4)$ & 133.61 & 16968 & \multirow[t]{2}{*}{7289.000} & \multirow[t]{2}{*}{0.17} \\
\hline & Kahoot & $3(2.4)$ & 121.39 & 15417 & & \\
\hline \multirow[t]{2}{*}{ Computer literacy skill was a barrier in online assessment } & Google Fill Out & $3(2.4)$ & 133.73 & 16984.00 & \multirow[t]{2}{*}{7273.000} & \multirow[t]{2}{*}{0.16} \\
\hline & Kahoot & $2(2.3)$ & 121.27 & 15401.00 & & \\
\hline
\end{tabular}

1-Strongly disagree, 2-Disagree, 3-Neutral, 4-Agree, 5-Strongly agree

Table 3: Attitude on online assessment

\begin{tabular}{|c|c|c|c|c|c|c|}
\hline Statement & Strongly disagree & Disagree & Neutral & Agree & Strongly agree & Median (IQ) \\
\hline Helped me in preparing the topic & $3(2.4)$ & $9(7.1)$ & $40(31.5)$ & $59(46.5)$ & $16(12.6)$ & $4(3.4)$ \\
\hline I have apprehension about online assessment & $2(1.6)$ & $9(7.1)$ & $63(49.6)$ & $44(34.6)$ & $9(7.1)$ & $3(3.4)$ \\
\hline Better than traditional assessment & $33(26)$ & $50(39.4)$ & $29(22.8)$ & $13(10.2)$ & $2(1.6)$ & $2(1.3)$ \\
\hline Good for self-directed learning & $8(6.3)$ & $11(8.7)$ & $25(19.7)$ & $69(54.3)$ & $14(11)$ & $4(3.4)$ \\
\hline Helped in receiving feedback from faculty & $6(4.7)$ & $13(10.2)$ & $49(38.6)$ & $48(37.8)$ & $11(8.7)$ & $3(3.4)$ \\
\hline Feedback makes me want to work better & $4(3.1)$ & $8(6.3)$ & $39(30.7)$ & $65(51.2)$ & $11(8.7)$ & $4(3.4)$ \\
\hline Feedback made me anxious & $10(7.9)$ & $18(14.2)$ & $56(44.1)$ & $35(27.6)$ & $8(6.3)$ & $3(3.4)$ \\
\hline Helped me to learn independently & $3(2.4)$ & $13(10.2)$ & $37(29.1)$ & $59(46.5)$ & $15(11.8)$ & $4(3.4)$ \\
\hline Time allotted was sufficient & $19(15)$ & $27(21.3)$ & $30(23.6)$ & $46(36.2)$ & $5(3.9)$ & $3(2.4)$ \\
\hline There is no enough time to prepare for assessments & $9(7.1)$ & $30(23.6)$ & $37(29.1)$ & $45(35.4)$ & $6(4.7)$ & $3(2.4)$ \\
\hline I attended the assessments sincerely & $2(1.6)$ & $26(20.5)$ & $36(28.3)$ & $49(38.6)$ & $14(11)$ & $3(3.4)$ \\
\hline I don't like online assessments & $14(11)$ & $33(26)$ & $38(29.9)$ & $31(24.4)$ & $11(8.7)$ & $3(2.4)$ \\
\hline
\end{tabular}

Table 4: Marks scored out of 50 in series of formative online assessments

\begin{tabular}{llllll}
\hline $\begin{array}{l}\text { Test series out } \\
\text { of 50 }\end{array}$ & $\mathbf{N}$ & Mean & $\mathbf{9 5 \%} \mathbf{C I}$ & Minimum & Maximum \\
\hline Test 1 (Kahoot) & 127 & 27.32 & $25.64-29.0$ & 10 & 50 \\
Test 2 (Kahoot) & 127 & 26.08 & $24.31-27.85$ & 7 & 50 \\
Test 3 (Kahoot) & 127 & 34.76 & $33.28-36.24$ & 11 & 46 \\
Test 1 (Google & 127 & 28.50 & $27.08-29.92$ & 16 & 50 \\
$\begin{array}{l}\text { Fill Out) } \\
\text { Test 2 (Google }\end{array}$ & 127 & 41.09 & $39.93-42.25$ & 18 & 50 \\
$\begin{array}{l}\text { Fill Out) } \\
\text { Test 3 (Google }\end{array}$ & 127 & 34.43 & $33.21-35.65$ & 20 & 50 \\
Fill Out) & & & & & \\
\hline
\end{tabular}

there was lot of cheating done by reattempting and not to make all questions compulsory and one participant blatantly suggested to stop the online assessments.

\section{DISCUSSION}

During the COVID-19 pandemic the potential to use Technologically Enhanced Active Learning in medical education has been tapped and analyzed [9]. Computer-based case simulations, model driven simulations, and virtual reality/haptic devices are some of the tested assessment methods available worldwide [10]. It has potential to contribute to different facets of educational and professional testing and to effective learning. It has been adopted successfully in medical curriculum teaching and learning along with the effects of the development of pervasive, high speed information, and knowledge in clinical and medical backgrounds [11]. The rich educational assessment with dynamic sounds and visuals, user interactivity, adaptability, improved reliability, and impartiality is some of the advantages of e assessments. Near real-time score reporting, instantaneous personalized feedback, time and space independence, and efficient data collection for statistical analysis are among the other advantage $[12,13]$. The use of computers makes the assessment easier, relieves the faculty of the burdensome task of invigilation and grading [14]. However, some researchers have also discussed the associated disadvantages of using computer technology with the perceived validity of CBA [15]. Universities worldwide have implemented such computer assisted assessment systems because of the obvious benefits when compared to traditional assessment methods both for formative, summative, and self-assessment purposes [16]. In this study, the participants attended formative online assessments on Google Forms and Kahoot Online platform. Both assessment platforms were opined to be somewhat convenient and easy to use with regard to ease of access, clarity of display of option, and overall user interface. The storage option was better for Google forms. Ease to enter answers was better for Kahoot which was statistically significant. However, considering the fact that short notes and short answers require more time in typing and answering compared to MCQs this opinion may be because of the use of MCQs and one word answers on Kahoot compared to MCQS, SAQ, short answers, and match the following on Google Forms. In this study, participants expressed privacy concerns and technical glitches with Google form as compared to Kahoot. However, there was equivocal response to the statements regarding network issues, eye strain, and computer literacy in both platforms. Lee and Weerakoon stated that the anxiety of computer use and experience in computer use has not been related to student performance [17]. Some studies have proposed that pilot testing as well as mock quizzes/tests would help the students to acquaint with the new assessment tool $[9,18]$.

Studies have shown that medical students have shown keen interest and have positive experience using online assessments for both formative and summative assessments [9,19-21]. Elzainy et al. stated that majority of the faculty in their study appreciated the tremendous 




Fig. 1: Practices adopted during online assessment

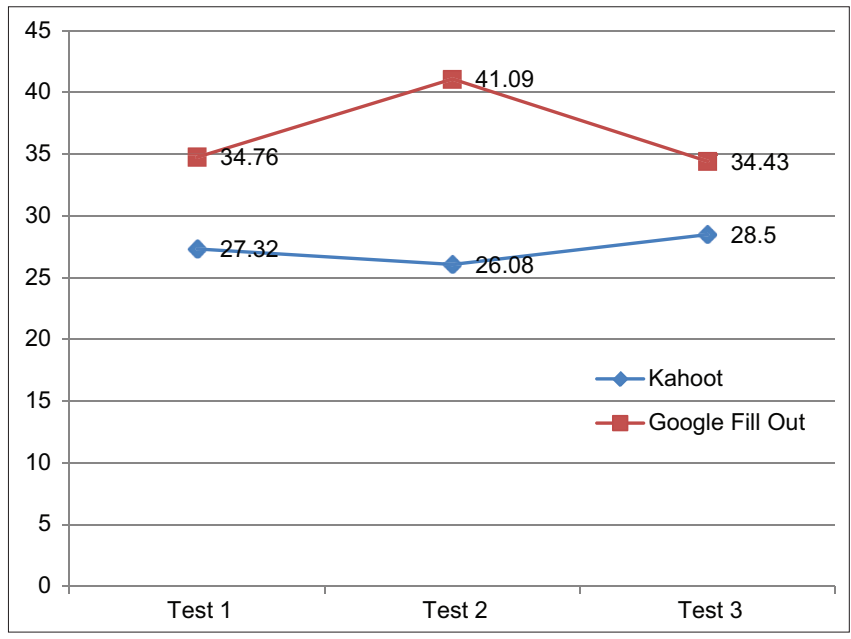

Fig. 2: Mean marks scored in formative online assessments

shift to implement online summative assessments as they could be assured of the attainment of learning outcomes in their students [9]. Kühbeck et al. proposed that online assessments provided valuable tool for both students and educators in higher education to model and predict the academic performance and intervene early for the at risk students [22]. However, in this study, even though majority agreed that online assessments helped and motivated them in topic preparation, self-directed learning, independent learning, and improvement through feedbacks they disagreed that online assessments were better than traditional assessment. Majority were neutral about the apprehension on attending online assessments or receiving feedbacks. Kühbeck et al. evaluated and found that online assessments improved the self-perceived pharmacology competence, there was gender neutrality with regard to preference online assessments and first attempt score and time per question were significant predictors of the final scores [22]. In the open ended question of this study many participants complained of inadequate time for preparation for assessments as well as inadequate time for submission of tests which affected time per question. During the COVID-19 lockdown, education providers all over the world had resorted to remote learning and online assessment despite the challenges and one major concern is the academic integrity [23]. Academic integrity is defined as "a commitment, even in the face of adversity, to six fundamental values: Honesty, trust, fairness, respect, responsibility, and courage" [24]. In this study, many participants agreed that they had copy pasted or referred to text books, notes, or internet while writing the exams. The reasons cited were time constraints in answering, unavailability of option for skipping unknown questions and the want for more scores. During this, COVID-19 pandemic many institutions have resorted to "take home exams" with an adequate window period of $24 \mathrm{~h}$ for submission of answer sheet, which can allow students to grapple with unexpected technical glitches [25]. There have also been instances of assessments as open book examinations worldwide $[4,26]$. The open book exams unlike the take home online exams have time constraints but they significantly reduced student anxiety and the final grades no longer an indicator of educational performance measure [23,26]. Birch and de Wolf stated that such assessments need to test the knowledge and problem solving ability of the student rather than their ability to Google [26]. The module on online learning and assessment rolled out by the National Medical Commission of India states that mid-course assessments help the students to self-assess, keep up with deadlines and give feedback to learners [27]. In a study by Sreedharan et al., the majority of the participants opined that they could not reproduce the content learned in the class even though it was well explained [28]. In a study by Kesavan and Palappallil, they concluded that well designed formative assessment can improve the outcome of summative assessment [29]. Formative assessments which can be routinely done after completion of a few units help to assess the performance of learners and provide feedback; however, in this COVID-19 pandemic it has helped the students to keep them motivated. Limitations of this study are that it was a single center study restricted to second phase medical undergraduates and the results are based on self-perceived feedback which could change over time.

\section{CONCLUSION}

The participants felt that Google Forms and Kahoot were comparable online assessment tools, online assessments were useful but not a replacement for traditional assessments and some participants had referred to various study materials and internet while attending the assessments because it was unsupervised. During the COVID-19 pandemic, the online learning and assessment have kept the medical students in the process of synchronous and asynchronous learning. Adoption of either proctored exams or open book exams with sufficient time can pave the way for a better culture in online assessments. 


\section{ACKNOWLEDGMENT}

We thank the students of 2018 batch MBBS students who participated in this study. We thank the State Board of Medical Research for funding this study.

\section{AUTHOR CONTRIBUTIONS}

Dhanya Sasidharan Palappallil-Project Idea, Study conductingPrepartion of Google Fill out Form and Kahoot Quiz (Pharmacology), Test evaluation, Literature Review, Data analysis, Statistical analysis, Manuscript preparation.

Deepa Sujatha-Protocol preparation, Study Conducting, Preparation of Google Fill out Form and Kahoot Quiz (Pathology), Manuscript Review.

\section{CONFLICT OF INTEREST}

No conflicts of interest to disclose.

\section{AUTHORS FUNDING}

This study was funded by State Board of Medical Research (SBMR), Government of Kerala, through Government Medical College, Kottayam.

\section{REFERENCES}

1. Joint Information Systems Committee (JISC). Effective Practice with E-Assessment; 2007. Available from: https://www.issuu.com/ jiscinfonet/docs/effective_practice_with_e-assessment_2007. [Last accessed on 2021 Mar 13].

2. Alruwais N, Wills G, Wald M. Advantages and challenges of using e-assessment. Int J Inform Educ Technol 2018;8:34-7.

3. Al-Amri S, Ali Z. Systematic review of computer based assessments in medical education. Saudi J Med Med Sci 2016;4:79-88.

4. Tapper J, Batty D, Savage M. Medical Students Take Final Exams Online for First Time, Despite Student Concern, The Guardian; 2020. Available from: https://www.theguardian.com/education/2020/mar/22/ coronavirus-forces-medical-students-sit-final-exams-online. [Last accessed on 2021 Jan 06].

5. Google Forms; 2021. Available from: https://www.en.wikipedia.org/ wiki/google forms. [Last accessed on 2021 Mar 13].

6. Kahoot! 2021. Available from: https://www.en.wikipedia.org/wiki/ kahoot!. [Last accessed on 2021 Mar 13].

7. Chanpet P, Chomsuwan K, Murphy E. Online project-based learning and formative assessment. Technol Knowl Learn 2018;25:685-705.

8. Kumar LR, Bedra A, Karkera R. Perception of medical students on E-assessment conducted through Yengage portal. Arch Med Health Sci 2013;1:61-6.

9. Elzainy A, Sadik AE, Abdulmonem WA. Experience of e learning and online assessment during the COVID-19 pandemic at the College of Medicine, Qassim University. J Taibah Univ Med Sci 2020;15:456-62.

10. Norcini JJ, McKinley DW. Assessment methods in medical education. Teach Teach Educ 2007;23:239-50.

11. Ward JP, Gordon J, Field MJ, Lehmann HP. Communication and information technology in medical education. Lancet 2001;357:792-6.

12. Thelwall M. Computerbased assessment: A versatile educational tool.
Comput Educ 2000;34:37-49.

13. Cantillon P, Irish B, Sales D. Using computers for assessment in medicine. BMJ 2004;329:606-9.

14. Sheader E, Gouldsborough I, Grady R. Staff and student perceptions of computer-assisted assessment for physiology practical classes. Adv Physiol Educ 2006;30:174-80.

15. Zakrzewski S, Bull J. The mass implementation and evaluation of computer-based assessments. Assess Eval High Educ 1998;23:141-52.

16. Thompson S, Thurlow M, Moore M. Using Computer-Based Tests with Students with Disabilities (Policy Directions No. 15). Minneapolis, MN: University of Minnesota, National Center on Educational Outcomes; 2002. Available from: http://www.files.eric.ed.gov/fulltext/ ed475318.pdf. [Last accessed on 2021 Mar 13].

17. Lee G, Weerakoon P. The role of computer-aided assessment in health professional education: A comparison of student performance in computer-based and paper and-pen-multiple-choice tests. Med Teach 2001;23:152-7.

18. Hassanien MA, AL-Hayani A, Abu-Kamer R, Almazrooa A. A six step approach for developing compute based assessment in medical education. Med Teach 2013;35 Suppl 1:S15-9.

19. Deutsch T, Herrmann K, Frese T, Sandholzer H. Implementing computer-based assessment-a web-based mock examination changes attitudes. Comput Educ 2012;58:1068-75.

20. Bandele SO, Oluwayato JA, Omodara MF. Opinions of undergraduates on the use of electronic examination in a Nigerian university. Mediterr J Soc Sci 2015;6:75-81.

21. Jawaid M, Moosa FA, Jaleel F. Computer based assessment (CBA): Perception of residents at Dow university of health sciences. Pak J Med Sci 2016;30:688-91.

22. Kuhbeck F, Berberat PO, Engelhardt S, Sarikas A. Correlation of online assessment parameters with summative exam performance in undergraduate medical education of pharmacology: A prospective cohort study. BMC Med Educ 2019;19:412.

23. Gamage KA, de Silva EK, Gunawardhana N. Online delivery and assessment during COVID-19: Safeguarding academic integrity. Educ Sci 2020;10:301

24. Internationnal Centre for Academic Integrity, Fundamental Values Project 2014; 2021. Available from: https://www.academicintegrity. org/fundamental-values. [Last accessed on 2021 Mar 13].

25. Canturbury Christ Church University. Available from: https://www. canterbury.ac.uk/current-students/academic-services/assessments/ exams-and-coursework. [Last accessed on 2021 Mar 13].

26. Birch E, de Wolf M. A novel approach to medical school examinations during the COVID-19 pandemic. Med Educ Online 2020;25:1785680.

27. National Medical Commission. Module on Online Learning and Assessment. New Delhi: National Medical Commission; 2020. p. 1-57. Available from: https:/www.nmc.org.in/mcirest/open/ getdocument?path=/documents/public/portal/latestnews/module-8online-learning-and-assessment-17-11-20-version-final-for-uploadingconverted.pdf. [Last accessed on 2021 Mar 13].

28. Sreedharan S, Palappallil DS, Veedu LK, Sankar HK, Divakaran AM. Assimilating and reproducing concepts after pharmacology lecture-a questionnaire-based study. Asian J Pharm Clin Res 2020;13:122-5.

29. Kesavan KP, Palappallil DS. Effectiveness of formative assessment in motivating and improving the outcome of summative assessment in pharmacology for medical undergraduates. J Clin Diagn Res 2018;12:FC08-11. 